\title{
SMART WIND TURBINE TIPE HORIZONTAL SUDU DATAR MULTIBLADE DENGAN MENGGUNAKAN ARDUINO SEBAGAI PENGATURAN SUDUT SUDU SECARA OTOMATIS
}

\author{
Elsa Khunaifi ${ }^{(1)}$, Rendi Pangestuningtyas ${ }^{(2)}$, Tanti Heriawati ${ }^{(3)}$ \\ Jurusan Teknik Mesin Politeknik NegeriSemarang \\ J1. Prof H. Sudarto, SH., Tembalang, Kotak Pos 6199/SMS, Semarang 50329 Telp. 7473417, 7499585 \\ (Hunting), Fax.7472396
}

\begin{abstract}
Abstrak
Angin merupakan salah satu potensi energi dimana sumber energinya tersedia dimanapun dan sangat murah. Kecepatan angin di Indonesia sangat bervariasi dan banyak yang menggunakan turbin angin tipe airfoil dengan tiga sudu. Turbin angin tipe airfoil hanya dapat beroperasi pada kecepatan angin tinggi sehingga perlu mendesain turbin yang mampu beroperasi pada kecepatan angin tinggi maupun rendah. Salah satunya dengan menciptakan Turbin AnginCerdas.Smart Wind Turbine dapat diwujudkan dengan membuat plan area sudu yang berubah-ubah secara otomatis. Perubahan pada plan area sudu turbin dilakukan dengan mengatur sudut pitch blade dimana saat plan area bertambah sudut pitch blade rendah sedangkan saat plan area berkurang sudut pitch blade tinggi. Oleh karena itu diciptakan Smart Wind Turbine dimana turbin tersebut dapat mengatur besar plan area sesuai kondisi kecepatan angin menggunakan system control dengan memanfaatkan teknologi arduino yang merupakan terknologi mutakhir yang dapat menyesuaikan variasi dari kecepatanangin.
\end{abstract}

Kata kunci : "Smart Wind Turbine”, "SistemKontrol”, "TeknologiMutahir”

\section{Pendahuluan}

Energi angin merupakan salah satu potensi energi terbarukan yang dapat memberikankontribussignifikan

terhadapkebutuhanenergilistrik domestik, khususnya wilayah terpencil. Pembangkit energi angin yang biasa disebut PembangkitListrikTenaga Bayu (PLTB) ini bebas polusi dan sumber energinya yaitu angin tersedia di mana pun, makapembangkit ini dapat menjawab masalah lingkungan hidup dan ketersediaan sumber energi. KecepatananginIndonesiasangat

bervariasi.Potensiangindengan kecepatan rendah menggunakan turbin angin sudu banyak tipe flat (diatas delapan sudu) yang memiliki plan area sudu tinggi untuk kecepatan angin rendah. Sedangkan untuk kecepatan angin tinggi menggunakan turbin angin tiga sudu dengan profil sudu airfoil. Turbin tipe ini memiliki plan area sudu rendah yang cocok untuk kecepatan angin tinggi.

Selama ini Indonesia menggunakan turbin angin tipe airfoil dengan tiga sudu seperti di Pantai Baru Bantul Yogyakarta dan di Tasikmalaya. Mengingat kecepatan angin di Indonesia bervariasi, maka memerlukan turbin angin yang mampu beroperasi di keadaan Indonesia. Hal ini menimbulkan gagasan baru untuk mendesain turbin angin yang mampu beroperasi di segala kecepatan angin dan dapat diwujudkan dengan membuat plan area sudu yang berubahubah secara otomatis. Saat kecepatan angin rendah plan area akan bertambah dan saat kecepatan angin tinggi plan area akan berkurang. Perubahan pada plan area sudu turbin dilakukan dengan mengatur sudut pitch blade dimana saat plan area bertambah sudut pitch blade rendah sedangkan saat plan area berkurang sudut pitch blade tinggi. Sudut sudu line coat terhadap $\mathrm{U}$, oleh karena itu diciptakan turbin angin cerdas dimana turbin tersebut dapat mengatur besar plan area sesuai kondisi kecepatan angin menggunakan system control dengan memanfaatkan teknologi arduino yang merupakan terknologi mutakhir. 


\section{Metode Penelitian}

Jenis penelitian yang digunakan adalah penelitian observasional karena menganalisa sudut serang terbaik dari turbin angin multiblade. Proses analisa meliputi analisa proses dan prinsip kerja dari turbin angin cerdas ini serta membandingkan beberapa sudut serang terbaik.

\section{Hasil yang Dicapai}

\subsection{Hasil Rancangan Turbin Angin Sudu Flat Multiblade}

Rancangan turbin angin sudu tipe flat multiblade yang telah dibuat dapat dilihat pada gambar 1. Dengan dimensi tinggi sebesar 1,205 $\mathrm{m}$ dan diameter sapuan sudu sebesar $0,78 \mathrm{~m}$. Komponen utama turbin angin terdiri dari (1) Sudu yang berfungsi untuk menerima energi kinetik dari angin dan merubahnya menjadi energi putar (energi mekanik) dengan panjang $300 \mathrm{~mm}$, lebar $50 \mathrm{~mm}$ dan tebal $2 \mathrm{~mm}$; (2) Piringan sudu yang berfungsi untuk menghubungkan sudu dengan poros dengan diameter masingmasing $180 \mathrm{~mm}, 150 \mathrm{~mm}, 60 \mathrm{~mm}$ dan tebal $50 \mathrm{~mm}, 30 \mathrm{~mm}, 40 \mathrm{~mm}$; (3) Sensor anemometer yang berfungsi sebagai pengukur kecepatan angin ; (4) Panel arduino yang berfungsi untuk mengendalikan input, proses dan output data ; (5) Servomotor yang berfungsi mengatur posisi sudut sudu secara otomatis ; (6) Kerangka atas yang berfungsi untuk tempat dimana sudu , cakram, poros, bearing berada dengan ukuran panjang 250 $\mathrm{mm}$, lebar $210 \mathrm{~mm}$ dan tinngi $230 \mathrm{~mm}$; (7) Kerangka bawah yang berfungsi untuk penyangga kerangka atas dengan tinggi $860 \mathrm{~mm}$, lebar bagian atas $280 \mathrm{~mm}$, lebar bagian bawah $740 \mathrm{~mm}$ dan panjang 320 mm.

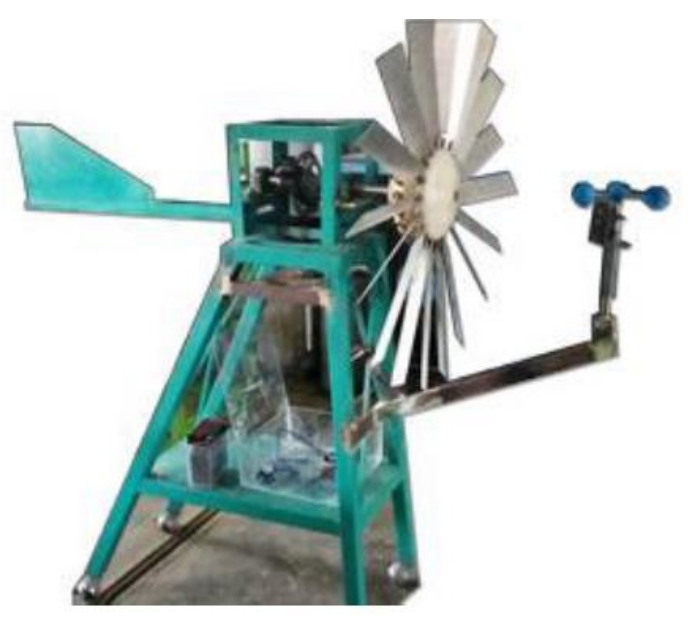

Gambar 1.HasilRancanganTurbin

\subsection{Data Hasil Pengujian Alat}

Setelah penyelesaian alat selanjutnya dilakukan pengujian alat ini. Pengujian dilakukan dengan tiga variasi sudut, yakni $30^{\circ}, 35^{\circ}, 40^{\circ}$ dan 450 , dan tiga variasi kecepatan angin $4 \mathrm{~m} / \mathrm{s}$ dan $7 \mathrm{~m} / \mathrm{s}$ dan 10 $\mathrm{m} / \mathrm{s}$. Dan didapatkan data sebagai berikut:

- Nilai CP terbaik pada kecepatan angin 4 $\mathrm{m} / \mathrm{s}$, yaitu pada sudut sudu 400 yakni 0,223056 (Gambar 2).

- Nilai CP terbaik pada kecepatan angin 7 $\mathrm{m} / \mathrm{s}$, yaitu pada sudut sudu 300 yakni 0,122752 (Gambar 3).

- Nilai CP terbaik pada kecepatan angin $10 \mathrm{~m} / \mathrm{s}$, yaitu pada sudut sudu 350 adalah 0.084712 (Gambar 3).

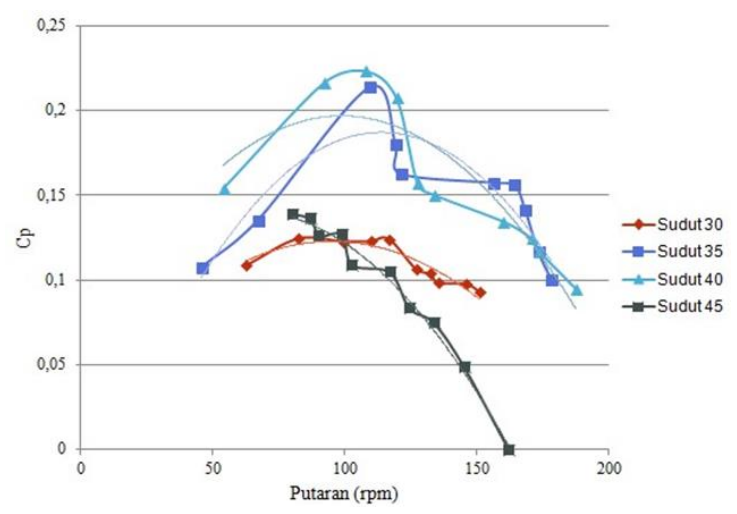

Gambar2.Grafik HasilNilai CpTurbin pada kecepatan $4 \mathrm{~m} / \mathrm{s}$ 
Tabel 1. HasilNilai CpTurbin pada kecepatan $4 \mathrm{~m} / \mathrm{s}$

\begin{tabular}{|c|c|c|c|}
\hline \multicolumn{2}{|c|}{ Sudut $30^{\circ}$} & \multicolumn{2}{c|}{ Sudut $35^{\circ}$} \\
\hline $\begin{array}{c}\text { Putaran } \\
\text { (rpm) }\end{array}$ & Cp & $\begin{array}{c}\text { Putaran } \\
\text { (rpm) }\end{array}$ & Cp \\
\hline 151 & 0.092975 & 178 & 0.09964 \\
\hline 145.5 & 0.097733 & 173 & 0.1162 \\
\hline 135.1 & 0.098309 & 168 & 0.14106 \\
\hline 132.2 & 0.103599 & 164 & 0.15606 \\
\hline 126.7 & 0.106381 & 156 & 0.15718 \\
\hline 116.5 & 0.123901 & 121 & 0.16255 \\
\hline 109.5 & 0.122586 & 119 & 0.17985 \\
\hline 99.4 & 0.122407 & 109 & 0.21355 \\
\hline 82.1 & 0.12408 & 67 & 0.13501 \\
\hline 62.5 & 0.108452 & 45.5 & 0.10697 \\
\hline Sudut $40^{\circ}$ & Sudut $45^{\circ}$ \\
\hline Putaran & Cp & Putaran & Cp \\
\hline (rpm) & (pm) & \\
\hline 187.4 & 0.094408 & 161.8 & 0 \\
\hline 173.5 & 0.11654 & 144.9 & 0.04866 \\
\hline 170.6 & 0.124142 & 133.5 & 0.07472 \\
\hline 159.9 & 0.134257 & 124.2 & 0.08342 \\
\hline 133.9 & 0.149902 & 116.8 & 0.10460 \\
\hline 127.4 & 0.156887 & 102.5 & 0.10901 \\
\hline 119.4 & 0.207187 & 98.7 & 0.12706 \\
\hline 107.7 & 0.223056 & 90.2 & 0.12622 \\
\hline 91.8 & 0.215818 & 86.8 & 0.13604 \\
\hline 53.8 & 0.153585 & 80.1 & 0.13899 \\
\hline
\end{tabular}

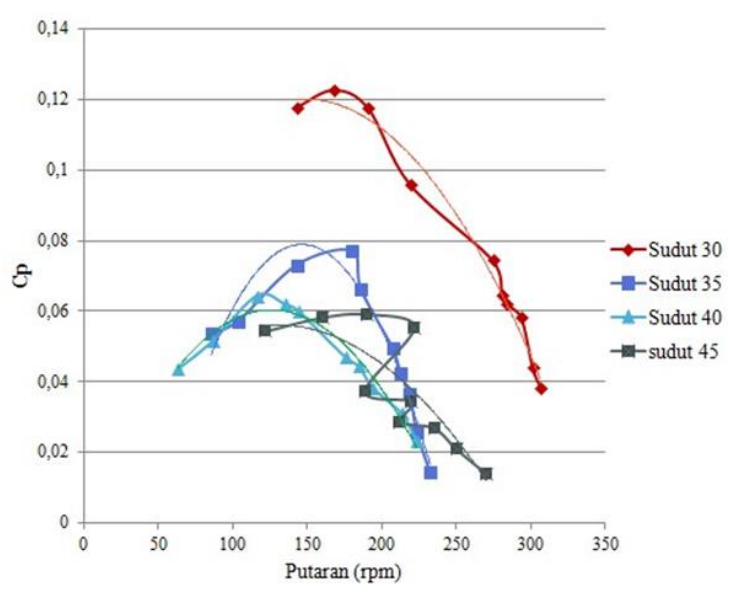

Gambar3.Grafik HasilNilai CpTurbin pada kecepatan $7 \mathrm{~m} / \mathrm{s}$
Tabel2. HasilNilai CpTurbin pada kecepatan $7 \mathrm{~m} / \mathrm{s}$

\begin{tabular}{|c|c|c|c|}
\hline \multicolumn{2}{|c|}{ Sudut $30^{\circ}$} & \multicolumn{2}{c|}{ Sudut $35^{\circ}$} \\
\hline $\begin{array}{c}\text { Putaran } \\
\text { (rpm) }\end{array}$ & Cp & $\begin{array}{c}\text { Putaran } \\
\text { (rpm) }\end{array}$ & Cp \\
\hline 306.3 & 0.038389 & 232.4 & 0.014564 \\
\hline 300.9 & 0.043998 & 223.5 & 0.025677 \\
\hline 293.3 & 0.058203 & 218.6 & 0.03653 \\
\hline 283.3 & 0.062137 & 212.7 & 0.042209 \\
\hline 280.4 & 0.064429 & 206.9 & 0.049702 \\
\hline 274.2 & 0.07446 & 185.9 & 0.066015 \\
\hline 218.9 & 0.096023 & 179.8 & 0.076994 \\
\hline 190.9 & 0.117636 & 142.6 & 0.072979 \\
\hline 167.9 & 0.122752 & 103.3 & 0.057182 \\
\hline 142.7 & 0.117742 & 85.6 & 0.053642 \\
\hline \multicolumn{2}{|c|}{ Sudut $40^{\circ}$} & Sudut $45^{\circ}$ \\
\hline $\begin{array}{c}\text { Putaran } \\
\text { (rpm) }\end{array}$ & Cp & Putaran & Cp \\
\hline 223.3 & 0.0233 & 269.9 & 0.014095 \\
\hline 213 & 0.0311 & 250.1 & 0.020897 \\
\hline 193.6 & 0.0384 & 234.8 & 0.026976 \\
\hline 184.6 & 0.0443 & 211.8 & 0.028757 \\
\hline 175.3 & 0.047 & 219.7 & 0.034419 \\
\hline 143.7 & 0.06 & 188.4 & 0.037387 \\
\hline 134.7 & 0.0619 & 221.6 & 0.055547 \\
\hline 116.2 & 0.0643 & 189.1 & 0.059251 \\
\hline 86.5 & 0.0515 & 159.4 & 0.058269 \\
\hline 63.2 & 0.0435 & 121 & 0.054342 \\
\hline
\end{tabular}

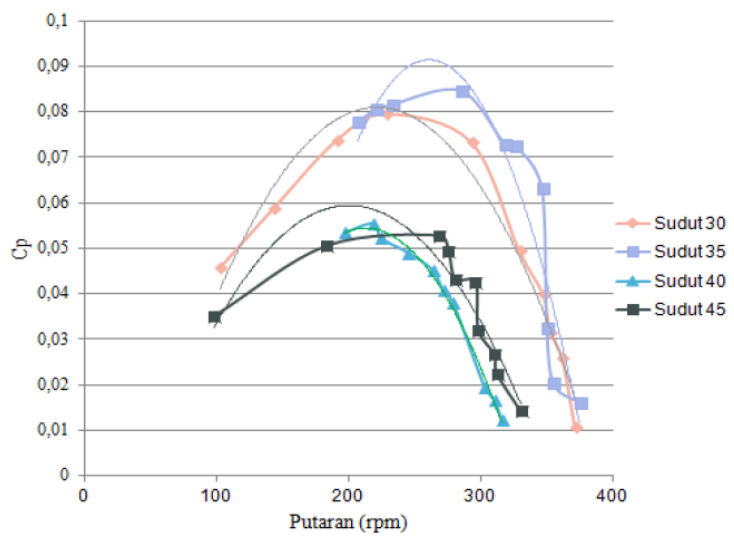

Gambar4.Grafik HasilNilai CpTurbin pada kecepatan $10 \mathrm{~m} / \mathrm{s}$ 
Tabel3. HasilNilai CpTurbin pada kecepatan $10 \mathrm{~m} / \mathrm{s}$

\begin{tabular}{|c|c|c|c|}
\hline \multicolumn{2}{|c|}{ Sudut $30^{\circ}$} & \multicolumn{2}{c|}{ Sudut $35^{\circ}$} \\
\hline $\begin{array}{c}\text { Putaran } \\
\text { (rpm) }\end{array}$ & Cp & $\begin{array}{c}\text { Putaran } \\
\text { (rpm) }\end{array}$ & Cp \\
\hline 371.4 & 0.010644 & 374.4 & 0.016095 \\
\hline 361.5 & 0.025901 & 354.8 & 0.020337 \\
\hline 352.5 & 0.03157 & 349.8 & 0.032581 \\
\hline 347.2 & 0.039802 & 346.1 & 0.063234 \\
\hline 329 & 0.049502 & 326.5 & 0.072519 \\
\hline 292.6 & 0.073375 & 318.2 & 0.072955 \\
\hline 228.9 & 0.079541 & 284.9 & 0.084712 \\
\hline 190.9 & 0.073859 & 232.4 & 0.08159 \\
\hline 143.1 & 0.058954 & 220.2 & 0.080462 \\
\hline 102.4 & 0.045855 & 206.8 & 0.077789 \\
\hline \hline \multicolumn{2}{|c|}{ Sudut $40^{\circ}$} & \multicolumn{2}{|c|}{ Sudut $45^{\circ}$} \\
\hline Putaran(r & Cp & Putaran(r & Cp \\
\hline pm) & pm) & \\
\hline 315.5 & 0.012433 & 330.1 & 0.014191 \\
\hline 309.8 & 0.016647 & 312.2 & 0.022369 \\
\hline 302.6 & 0.019513 & 310.1 & 0.026662 \\
\hline 278.8 & 0.037954 & 297.9 & 0.032016 \\
\hline 271.1 & 0.04079 & 295.9 & 0.042401 \\
\hline 263.1 & 0.045242 & 280.3 & 0.043178 \\
\hline 244.4 & 0.04903 & 275.3 & 0.049312 \\
\hline 224.2 & 0.052207 & 267.6 & 0.052726 \\
\hline 218.1 & 0.055474 & 182.9 & 0.050452 \\
\hline 196.6 & 0.053527 & 98 & 0.035108 \\
\hline
\end{tabular}

Pada data didapatkan nilai yang cukup rancu pada pengujian kecepatan angin 4 $\mathrm{m} / \mathrm{s}$ karena nilai CP terbaik ada pada sudut sudu 400 yang seharusnya nilai sudutnya lebih kecil daripada kecepatan angin $7 \mathrm{~m} / \mathrm{s}$ dan $10 \mathrm{~m} / \mathrm{s}$, sehingga perlu pengujian lebih lanjut untuk pengujian sudut sudunya, sebelum diubah menjadi bahasa program kemudian diinputkan ke mikrokontroller.

\subsection{Pengontrolan Sudut Sudu Turbin}

Data hasil pengolahan yang telah dirubah menjadi grafik selanjutnya akan diinput kedalam program kontrol dimana setiap kecepatan angin hanya diambil satu sudut dengan kurva tertinggi. Sistem menggunakan sumber DC 12 volt dari akumulator, setelah itu distep down menjadi 7 volt. Sumber ini di paralel menjadi 3 bagian yakni untuk sumber dari dua servo dan sumber dari satu step down, kemudian sumber 7 volt di step downkembali menjadi 5 volt dan di paralel menjadi 3 bagian yakni untuk sumber dari arduino, sumber dari LCD 2 x 16 dan sumber dari sensor kecepatan angin. Untuk penggunaan pin data, sensor kecepatan angin pada pin 2 , servomotor 1 pada pin 3 dan servomotor 2 pada pin 4, dan juga dengan penggunaan pin analog untuk LCD yakni SDA pada A5 dan SCL pada A4 (Gambar 5). Berdasarkan proses wiring diagram tersebut, maka dapat digambarkan blok diagram dengan sistem close loop (Gambar 6).

Berdasarkan gambar diagram blok tersebut, input data berupa kecepatan angin. Data tersebut diperoleh dari sensor kecepatan angin untuk diproses pada arduino agar servomotor bergerak sesuai dengan posisi sudut yang telah ditentukan sehingga sudut blade berubah. Dengan feedback berupa data dari sensor kecepatan angin, maka jika perubahan nilai data, arduino akan memproses kembali untuk mengubah sudut blade. Nilai sudutitu dirange antara sudut sudu dengan kecepatan angin dengan diagram alir seperti pada gambar 7 . 


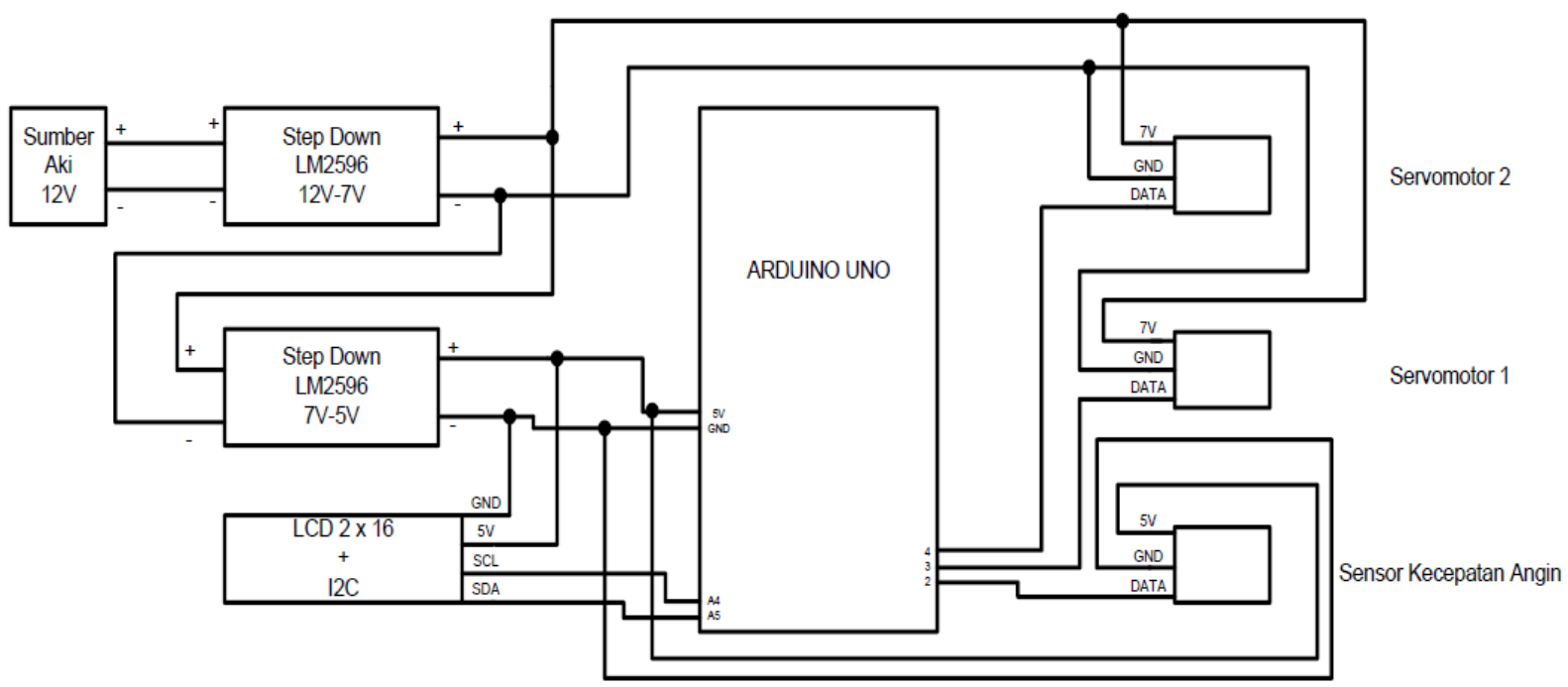

Gambar 5. Wiring Diagram Rangkaian Kontrol Turbin

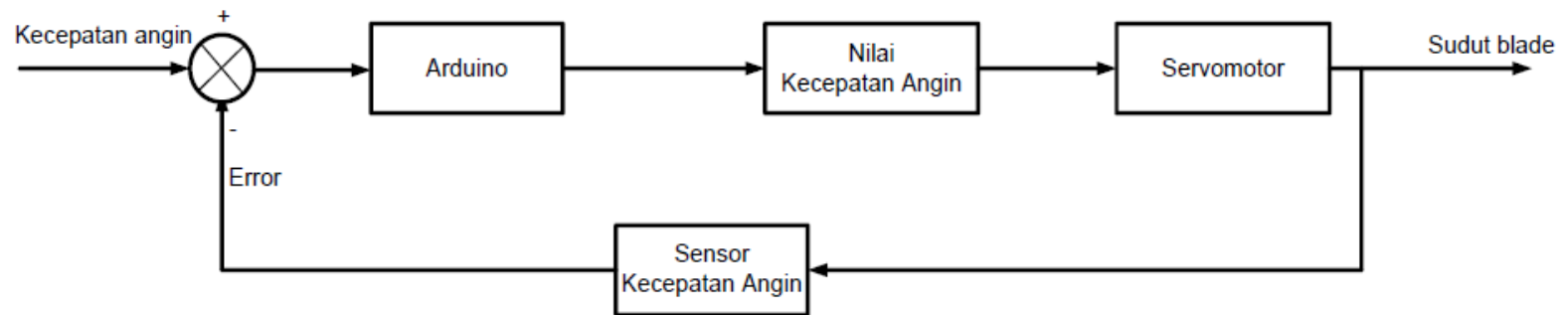

Gambar 6. Diagram Blok Pengaturan 


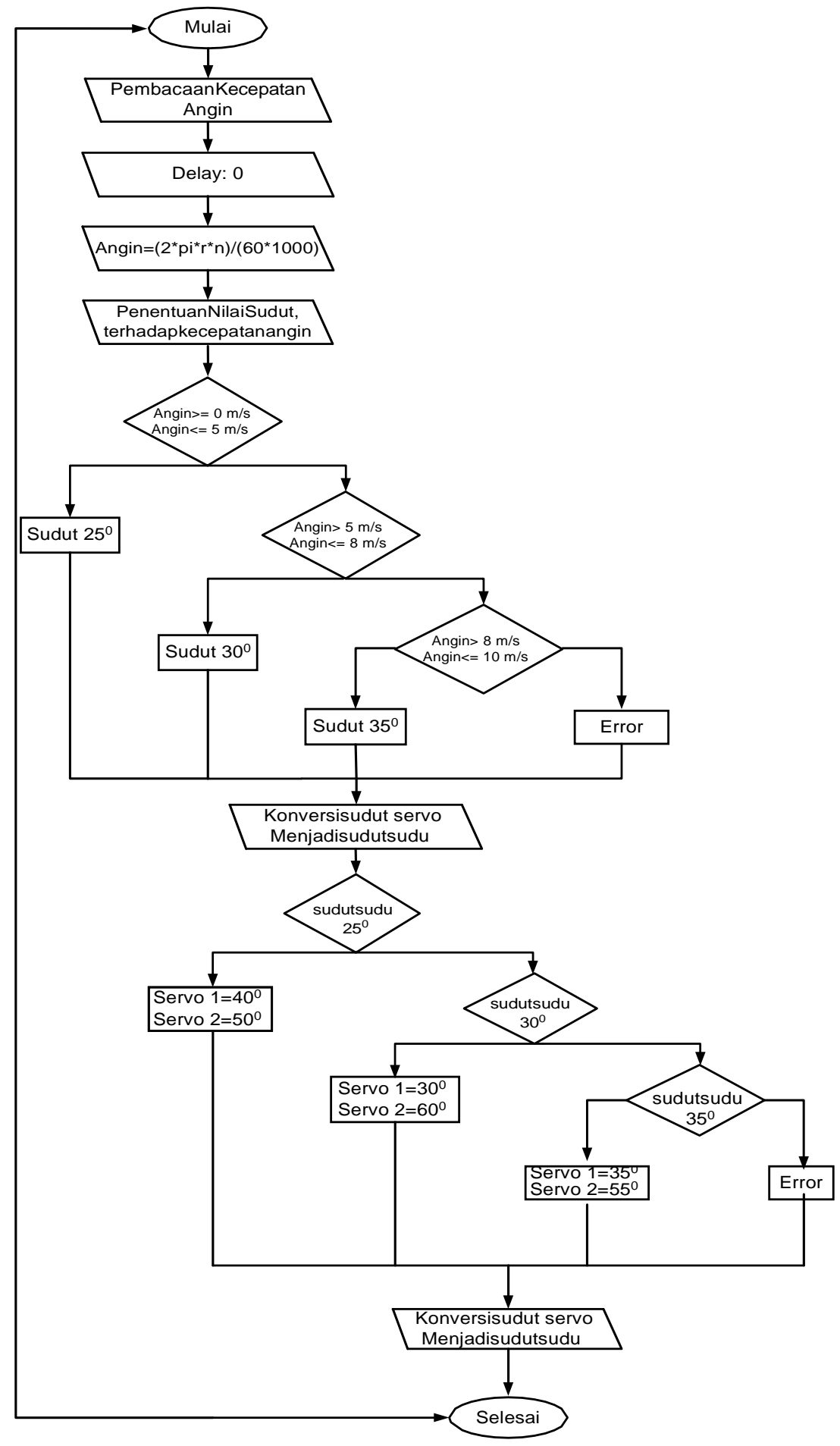

\section{Kesimpulan}

1. Turbin angin sudu flat multiblade memiliki 18 buah sudu dengan menggunakan bahan plat galvanum. Dimensi sudu, panjang : $300 \mathrm{~mm}$; lebar : $50 \mathrm{~mm}$; tebal : $2 \mathrm{~mm}$. Piringan sudu (hub) terbuat dari 3 buah nilon dengan dimensi : diameter masing - masing piringan sudu
$180 \mathrm{~mm}, 180 \mathrm{~mm}, 60 \mathrm{~mm}$ dan ketebalan masing - masing $50 \mathrm{~mm}, 30 \mathrm{~mm}, 40 \mathrm{~mm}$.

2. Berdasarkan grafik karakteristik hubungan putaran poros dengan $\mathrm{Cp}$ didapatkan :

a. Pada kecepatan $4 \mathrm{~m} / \mathrm{s}$ nilai $\mathrm{Cp}$ terbaik pada sudut sudu $25^{\circ}$ yaitu sebesar 0,289934 . 
b. Pada kecepatan $7 \mathrm{~m} / \mathrm{s}$ nilai $\mathrm{Cp}$ terbaik pada sudut sudu $30^{\circ}$ yaitu sebesar 0,0122752 .

c. Pada kecepatan $10 \mathrm{~m} / \mathrm{s}$ nilai $\mathrm{Cp}$ terbaik pada sudut sudu $35^{\circ}$ yaitu sebesar 0,084712 .

3. Berdasarkan grafik hubungan presentase kinerja pada sensor anemometer dan aktuator didapatkan presentase keakuratan masing-masing sebesar 99,4\% dan 93,3\%.

4. Sesuai grafik karakteristik hubungan antara Coefficient of Power $(\mathrm{Cp})$ terhadap putaran (rpm) sesuai gambar 4.2, 4.2, dan 4.4 menunjukkan bahwa semakin tinggi kecepatan angin maka akan memerlukan sudut sudu yang semakin besar sesuai dengan puncak-puncak $\mathrm{Cp}$.

\section{Daftar Pustaka}

- Adriansyah, Andi, \& Oka H. (2013). Rancang Bangun Prototipe Elevator Menggunakan Microcontroller Arduino Atmega 328p. Jurnal Teknologi Elektro Universitas Mercu, 4, 102.

- Aerotrope Limited. 2017. Riva Calzoni M33 Single Bladed Wind Turbine. New England House Brighton BN1 4GH UK.

- Belajar Elektronik. 2017. Pengertian PCB dan Fungsinya Serta JenisJenisnya.

http://belajarelektronika.net/pengertianpcb-dan-fungsinya, (7 Agustus 2018). (Internet)

- Echo. 2017. Tower Pro Servomotor MG996R.

https://dealmarkaz.pk/electronics/otherelectronics/towerpro-servo-motor- mg996r-i4961, (6 Agustus 2018). (Internet)

- EngineersGarage. 2012. LCD. https://www.engineersgarage.com/electr onic-components/16x2-lcd-moduledatasheet, (7 Agustus 2018). (Internet)

- Freris, L.L. 1990. Wind Energy Conversion Sistems. Prentice Hall.

- Hau, Erich. 2006. Wind Turbines. Fundamental, Technologies, Application, Economics 2nd edition. Springer.

- Hobbytronics. 2018. Jumper Wires Male/Female $10 \mathrm{~cm} . \mathrm{n}$ http://www.hobbytronics.co.uk/jumperwires-mf-10cm, (7 Agustus 2018). (Internet)

- Holmes, Mark. 2014. Natural Fibre Reinforced Plastic Blades Used For Rooftop Wind Turbine. Material Today.

- J.F. Manwell, J.G. Mc Gowan and A.L. Rogers. 2002. Wind Energy Explained: Theory, Design and Application. Chichester : John Wiley Sons Ltd.

- M., Sophia Anne, Tyler G. 2015. Whats Up with Wind Turbines. Developing Agriculture's Future Leaders and Scientists.

- Solarbotics Ltd. 2018.Men Pin Strip.https://solarbotics.com/product/mp in3, (6 Agustus 2018). (Internet)

- Solarbotics Ltd. 2018.Buck Converter With LED Display. https://solarbotics.com/product/40400, (6 Agustus 2018). (Internet)

- Sukayan, Yayan. 2012. Bagian-Bagian Aki Kering dan Aki Basah. https://yayansukayan.wordpress.com/20 12/01/11/bagian-bagian-aki-kering-danaki-basah, (7 Agustus 2018).(Internet) 